\title{
Structural, Optical and Electrochromic Properties of Sputter Deposited Tungsten Oxide Films in Argon-Helium Atmosphere
}

\author{
Vyomesh R Buch* \\ CHAMOS Matrusanstha Department of Mechanical Engineering, \\ Chandubhai S. Patel Institute of Technology (CSPIT), \\ Charotar University of Science and Technology (CHARUSAT), Changa-388421, Gujarat, India \\ Sushant K Rawal \\ McMaster Manufacturing Research Institute, Department of Mechanical Engineering, \\ McMaster University, 1280 Main Street West, Hamilton, ON, L8S 4L7, Canada \\ Amit Kumar Chawla \\ Institute of Nanoscience and Nanotechnology, University of Petroleum and Energy Studies, \\ Energy Acres, Dehradun -248 007, Uttarakhand, Gujarat, India \\ (Received 15 February 2018; Accepted 19 May 2018; Published 16 June 2018)
}

\begin{abstract}
Tungsten oxide $\left(\mathrm{WO}_{3}\right)$ films have been deposited on glass substrates by radio frequency magnetron sputtering of tungsten target. We examined the effect of oxygen flow rate in argon and helium atmosphere on the structural, optical, and electrochromic properties of $\mathrm{WO}_{3}$ films. When helium gas is replaced with argon, the particle sizes and the band gap will get affected. Band gap values were obtained over a range of $2.62 \mathrm{eV}$ to $3.09 \mathrm{eV}$. The atomic mass of the sputtering gas also plays a prime role in changing the primary crystallite size, orientation, as well as band gap. We could relate the crystallization of tungsten atoms with low oxygen flow rate when films are deposited in helium instead of argon due to Penning ionization. [DOI: 10.1380/ejssnt.2018.289]
\end{abstract}

Keywords: Tungsten oxide; Radio frequency magnetron sputtering; Electrochromic; Band gap; Cyclic voltammetry

\section{INTRODUCTION}

Transition metal oxide thin films are of great technological importance due to their important applications such as electrochromic devices. Among the transition metal oxides, tungsten oxide $\left(\mathrm{WO}_{3}\right)$ is categorized as an n-type semiconductor as it shows good electrochromic properties in the visible and infrared regions, has low power consumption, and has high coloration efficiency and memory effects under open circuit conditions. Various deposition methods have been used to prepare $\mathrm{WO}_{3}$ films like thermal evaporation [1], anodic oxidation [2], spray pyrolysis [3], sol-gel [4], and molecular beam deposition [5] and sputtering [6].

Among these methods, sputtering can deposit uniform films on large area substrates [7]. In sputtering, the surrounding gases and the reaction between the gases and material surface are responsible for the physical properties of $\mathrm{WO}_{3}$ film. Thin films of $\mathrm{WO}_{3}$ have good electrical conductivity and are used for gas sensing application [7]. Several authors pointed out the influence of oxygen partial pressure on physical properties such as conductivity, surface morphology, chemical composition, and optical properties [8-12]. It was also observed that metallic target produces good crystalline oxide film by radio frequency (RF) magnetron sputtering [7]. Similar studies for other sputter-deposited films, specifically in helium, are quite rare. The aim of this paper is to show the effect of various sputtering gases (argon and helium) along with oxygen flow rate to study its surface morphology, optical, electrochromic, and wettability of $\mathrm{WO}_{3}$ films.

\footnotetext{
* Corresponding author: vyomdhar 19@yahoo.co.in
}

\section{EXPERIMENTAL DETAILS}

\section{A. Film deposition}

The $\mathrm{WO}_{3}$ films were deposited on Corning glass substrates at $450^{\circ} \mathrm{C}$ temperature by radio frequency magnetron sputtering method using pure tungsten metal target $(99.99 \%)$ under different oxygen gas flow rates. The chamber was initially evacuated to a base pressure of $6 \times 10^{-4} \mathrm{~Pa}$. Thereafter, high purity oxygen along with argon and helium was bled into the chamber. The required amount of gases were admitted into the custom designed chamber (Excel Instruments, India) by using fine controlled needle valves, and their flow rate was monitored individually by employing mass flow controller procured from Alicat Scientific (USA). The deposition was carried out by varying the flow of sputtering gases while keeping other sputtering parameters constant, as shown in Table I.

\section{B. Characterization}

The crystal structure and the structural properties of $\mathrm{WO}_{3}$ films were investigated using X-ray diffractometer

TABLE I. Deposition parameters for preparing tungsten oxide thin films.

\begin{tabular}{ll}
\hline \hline Sputter target & $\begin{array}{l}\text { Tungsten } \\
(50 \mathrm{~mm} \text { diameter, 2 mm thickness })\end{array}$ \\
Target to substrate distance & $50 \mathrm{~mm}$ \\
Base pressure & $6 \times 10^{-4} \mathrm{~Pa}$ \\
Sputtering pressure & $2.0 \mathrm{~Pa}$ \\
Sputtering power & $100 \mathrm{~W}$ \\
Substrate temperature & $450^{\circ} \mathrm{C}$ \\
\hline
\end{tabular}



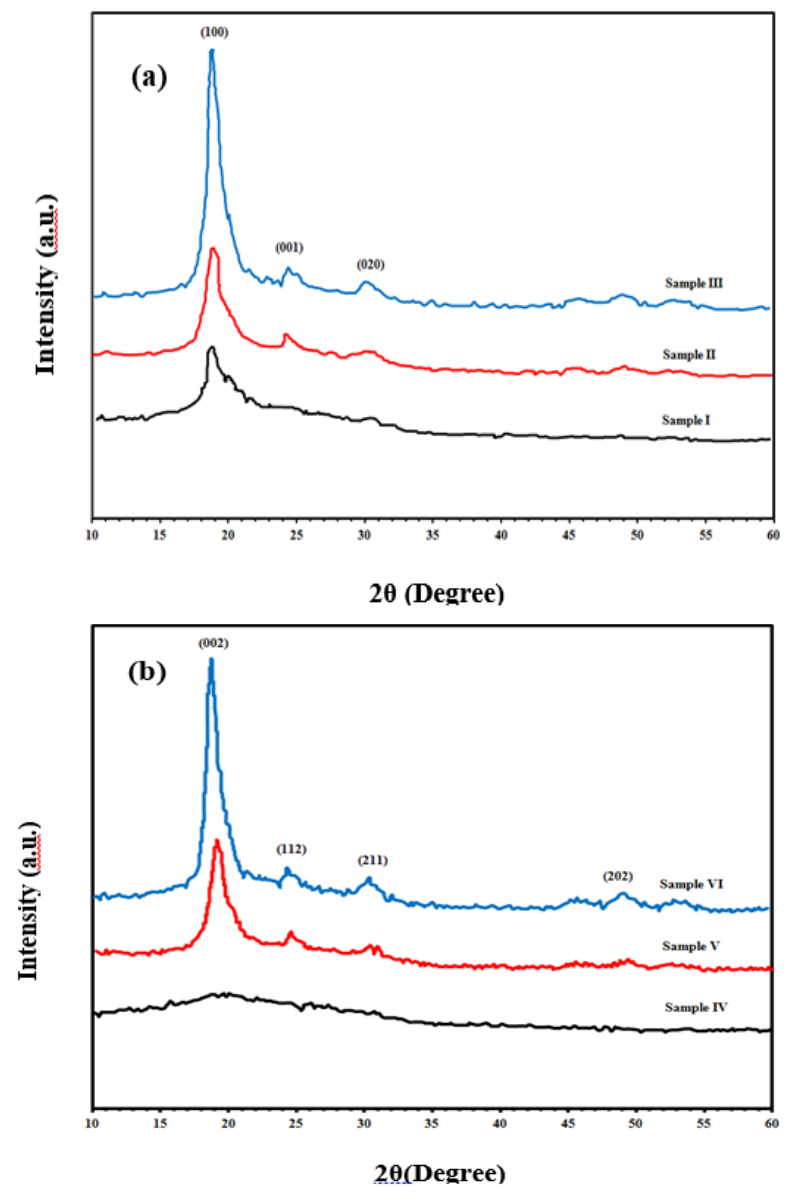

FIG. 1. XRD plot of tungsten oxide films deposited at different oxygen flow rates in (a) argon and (b) helium atmospheres.

(XRD) (Bruker, Model D2 Phase) with $\mathrm{Cu} \mathrm{K} \alpha$ radiation having wavelength $1.54 \AA$. Transmittance and absorption properties of $\mathrm{WO}_{3}$ films were measured in the wavelength range of $200-800 \mathrm{~nm}$ using Ultraviolet-Visible-NIR spectrophotometer (Shimadzu, Model UV-3600 plus). Electrochemical and electrochromic properties were assessed in $0.01 \mathrm{M} \mathrm{H}_{2} \mathrm{SO}_{4}$ with platinum as the counter electrode and $\mathrm{Ag} / \mathrm{AgCl}$ as the reference electrode. The cyclic voltammetry $(\mathrm{CV})$ measurements were performed at a scan rate of $0.02 \mathrm{mV} \mathrm{s}^{-1}$ between $-2.0 \mathrm{~V}$ and $+2.0 \mathrm{~V}$. The dynamic contact angle of distilled water on the coated film was measured by contact angle measuring system (Ramehart, Model 290). Samples I, II, and III were deposited in the argon-oxygen environment by varying the oxygen flow rates of 2,4 , and $6 \mathrm{sccm}$, respectively, while samples $\mathrm{IV}, \mathrm{V}$, and VI were deposited in the helium-oxygen environment by varying oxygen flow rates of 2,4 , and $6 \mathrm{sccm}$, respectively.

\section{RESULTS AND DISCUSSION}

\section{A. Physical and structural properties}

$\mathrm{WO}_{3}$ films were deposited by varying the oxygen flow rate at a fixed substrate temperature of $450^{\circ} \mathrm{C}$ and $150 \mathrm{~W}$ sputtering power in argon and helium atmospheres.

Figure 1(a) shows XRD graphs of $\mathrm{WO}_{3}$ films deposited in an argon atmosphere with varying oxygen flow rates.
From Fig. 1(a), it was observed that at low oxygen flow rate, the film (sample I) has mixed phase ( $\mathrm{W}$ and $\mathrm{WO}_{3}$ ) and randomly oriented phases (monoclinic). With the increase in oxygen flow rate, the rest of films (samples II, III) become single phase, and the tungsten atoms are oxidized completely for sample II and III films. So samples II and III show crystalline crystal structure, whereas tungsten atoms are not oxidized completely for sample I.

Figure 1 (b) shows $\mathrm{WO}_{3}$ films deposited in a helium atmosphere at varying oxygen flow rates. It was observed that at low oxygen flow rate, the (sample IV) thin film is amorphous and turns into crystalline with (002) orientation when the peaks turn crystalline. The $\mathrm{WO}_{3}$ films deposited in helium atmosphere are crystalline as compared to the films deposited in argon atmosphere due to the penning ionization process. The penning ionization process occurs in plasma. In this process, some particles in the ground state, such as oxygen, get ionized and transfer energy to the rare gas atoms, which are in neutral excited metastable states. Among all the rare gases, it was observed that helium gets excited in the neutral metastable state compared to other rare gases and transfer the highest amount of energy [13]. So, if any of the oxide films are deposited in helium gas by reactive magnetron sputtering process, then there is a possibility of the reaction between metal atoms and oxygen, which may result in the passing of activated oxygen atoms through the penning ionization process. So when $\mathrm{WO}_{3}$ films are deposited in a helium atmosphere, it easily oxides oxygen atoms leading to the formation of crystalline films as compared to films deposited in an argon atmosphere.

The average crystallite size $d$ of $\mathrm{WO}_{3}$ film was measured by using Scherrer formula [14]. In Table II, the calculated average crystallite sizes are shown. It was observed that the films deposited in a helium-oxygen environment have smaller particle size compared to the films deposited in the argon-oxygen environment. This can be explained on the basis of the mean free path. In the mean free path equation, as the size of the sputtering gas atoms increases, the mean free path of the inert gas atoms decreases, and hence, the collision frequency increases. So, we can say that the number of tungsten atoms would go under multiple collisions, and hence, there is a higher probability of agglomeration and growth even before arriving at the substrate. In such cases, we would expect an increase in the particle size with increase in atomic mass of the sputtering gas [15].

\section{B. Optical properties}

The transmittance spectra of the samples deposited in argon and helium environment with different oxygen flow rates are shown in Fig. 2(a, b). Due to interference effect within a wavelength, oscillations were observed in the spectrum. It was observed that with an increase in oxygen flow rate, the transmittance of $\mathrm{WO}_{3}$ films increases. From the literature, it was observed that the optical transmittance of the $\mathrm{WO}_{3}$ films depends on the oxygen content of the films $[13,16]$. At elevated oxygen pressure, the deposited film shows higher transparency, which may be attributed to a decrease in oxygen density. No effect of inert gas was seen on transparency except when deposition 
TABLE II. Calculated parameters of the tungsten oxide thin films.

\begin{tabular}{cccccc}
\hline \hline Sample name & Sputtering gas & Avg. $d(\mathrm{XRD})(\mathrm{nm})$ & Band gap $(\mathrm{eV})$ & Reflactive index $(n)$ & Thickness $(\mathrm{nm})$ \\
\hline $\mathrm{I}$ & $\mathrm{Ar}+2 \mathrm{sccm} \mathrm{O}_{2}$ & 15.4 & 2.62 & NIL & 2.85 \\
II & $\mathrm{Ar}+4 \mathrm{sccm} \mathrm{O}_{2}$ & 14.7 & 2.84 & 2.92 & 688 \\
$\mathrm{III}$ & $\mathrm{Ar}+6 \mathrm{sccm} \mathrm{O}_{2}$ & 14.4 & 2.93 & 2.89 & 831 \\
$\mathrm{IV}$ & $\mathrm{He}+2 \mathrm{sccm} \mathrm{O}_{2}$ & $\mathrm{NIL}$ & 2.83 & 2.98 & 291 \\
$\mathrm{~V}$ & $\mathrm{He}+4 \mathrm{sccm} \mathrm{O}_{2}$ & 9.4 & 3.04 & 2.96 & 312 \\
VI & $\mathrm{He}+6 \mathrm{sccm} \mathrm{O}_{2}$ & 9.8 & 3.09 & 470 \\
\hline \hline
\end{tabular}
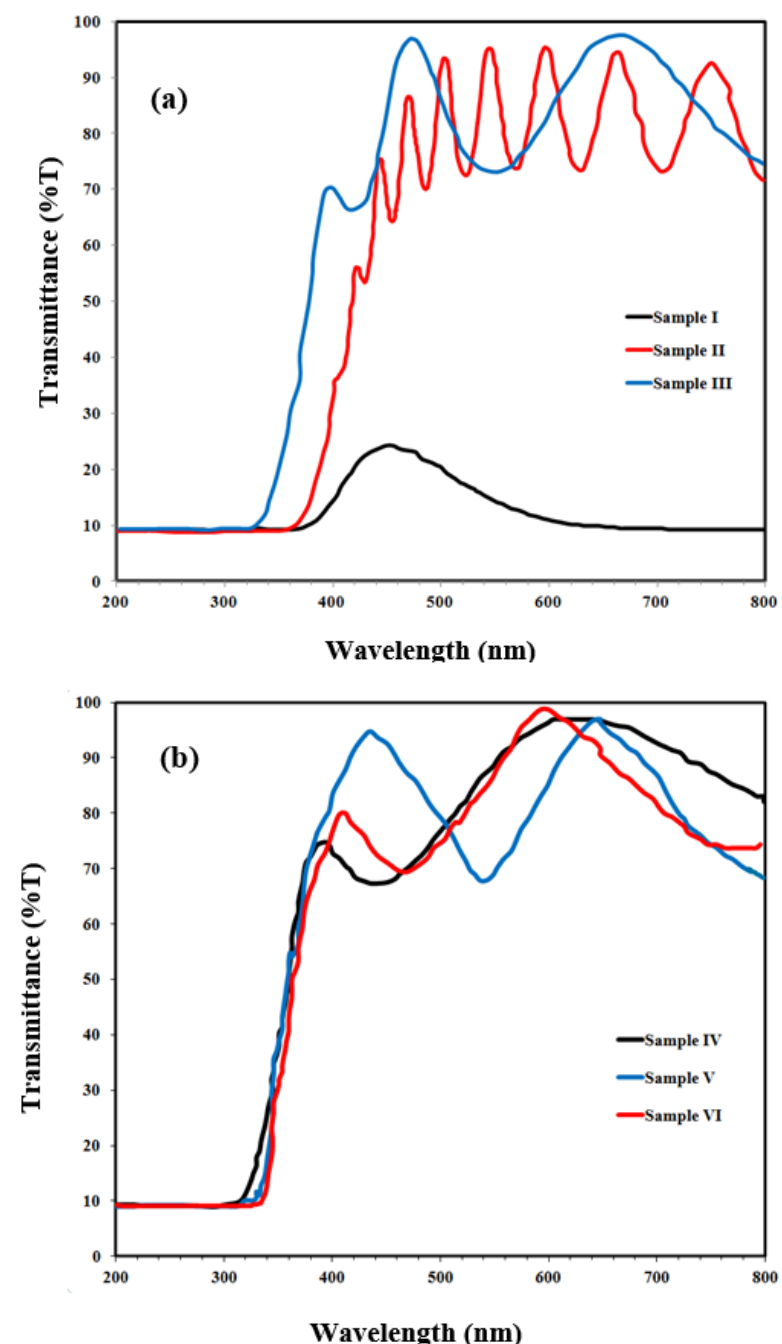

FIG. 2. Transmission spectra of tungsten oxide films deposited at different oxygen flow rates in (a) argon and (b) helium atmospheres.

carried out with argon environment for 2 sccm oxygen flow rate.

The maximum transparency of the film deposited in the argon-oxygen atmosphere with 2 sccm oxygen flow rate is $\sim 30 \%$ because of the presence of oxygen vacancies associated with tungsten ions in lower oxidation states than expected in $\mathrm{WO}_{3}$ stoichiometry. This may be the reason for the blue color of the sample while the rest are transparent [17]. From transmission data, the refractive index can be obtained by the model suggested by Manifacier et al. [18] This model shows the relationship between refractive index and the maximum and minimum transmittance of the film in terms of the equation given below;

$$
n=\left[N+\left(N^{2}-n_{0}^{2} n_{1}^{2}\right)^{1 / 2}\right]^{1 / 2}
$$

where

$$
N=\frac{n_{0}^{2}+n_{1}^{2}}{2}+2 n_{0} n_{1} \frac{T_{\max }-T_{\min }}{T_{\max } T_{\min }},
$$

where $n_{0}$ and $n_{1}$ are the refractive indices of air and the substrate (glass), respectively. The equation shows that the refractive index $n$ of the $\mathrm{WO}_{3}$ films can be explicitly determined from $T_{\max }, T_{\min }, n_{0}$, and $n_{1}$ at the same wavelength. The calculated refractive index is given in Table II. The thickness of the deposited films was examined by using the below relation;

$$
t=\frac{M \lambda_{1} \lambda_{2}}{2\left[n\left(\lambda_{1}\right) \lambda_{2}-n\left(\lambda_{2}\right) \lambda_{1}\right]},
$$

where $M$ is the number of the oscillations between the two extrema $(M=1)$ for two consecutive maxima or minima; $\lambda_{1}, n\left(\lambda_{1}\right)$ and $\lambda_{2}, n\left(\lambda_{2}\right)$ are the corresponding wavelength and indices of refraction. Thickness calculations (Table II) show that the film deposited in argon environment is $4-5$ times thicker than the film deposited in a helium environment. By considering the wavelength as a function, the absorption spectra of $\mathrm{WO}_{3}$ were recorded. We have used the Tauc relation [19] for the determination of the optical band gap $\left(E_{\mathrm{g}}\right)$ of $\mathrm{WO}_{3}$ films, and it is given by

$$
\alpha h \nu=B\left(h \nu-E_{\mathrm{g}}\right)^{m},
$$

where $h \nu$ is the photon energy of the incident beam and $E_{\mathrm{g}}$ is the value of the optical band gap corresponding to transitions indicated by the value $m$, which is characteristic of the type of the optical transition process [20,21]. Hegab et al. observed that the power parameter $m$ has the value of 2 for indirect optical transition and $1 / 2$ for a direct allowed optical transition [20]. The literature has widely stated that $\mathrm{WO}_{3}$ is an indirect band gap semiconductor having $m=2$ [22].

The value of factor $B$ depends on the transition probability, and it is assumed to be constant within the optical frequency range. Figure $3(\mathrm{a}, \mathrm{b})$ shows optical absorption of $\mathrm{WO}_{3}$ films deposited by using different sputtering gases. An extrapolation of the linear region of a plot of $(\alpha h \nu)^{1 / 2}$ on the $y$-axis versus photon energy $(h \nu)$ on the $x$-axis gives the value of the optical band gap $E_{\mathrm{g}}$ since $E_{\mathrm{g}}=h \nu$ when $(\alpha h \nu)^{1 / 2}=0$. Chawla et al. reported that 

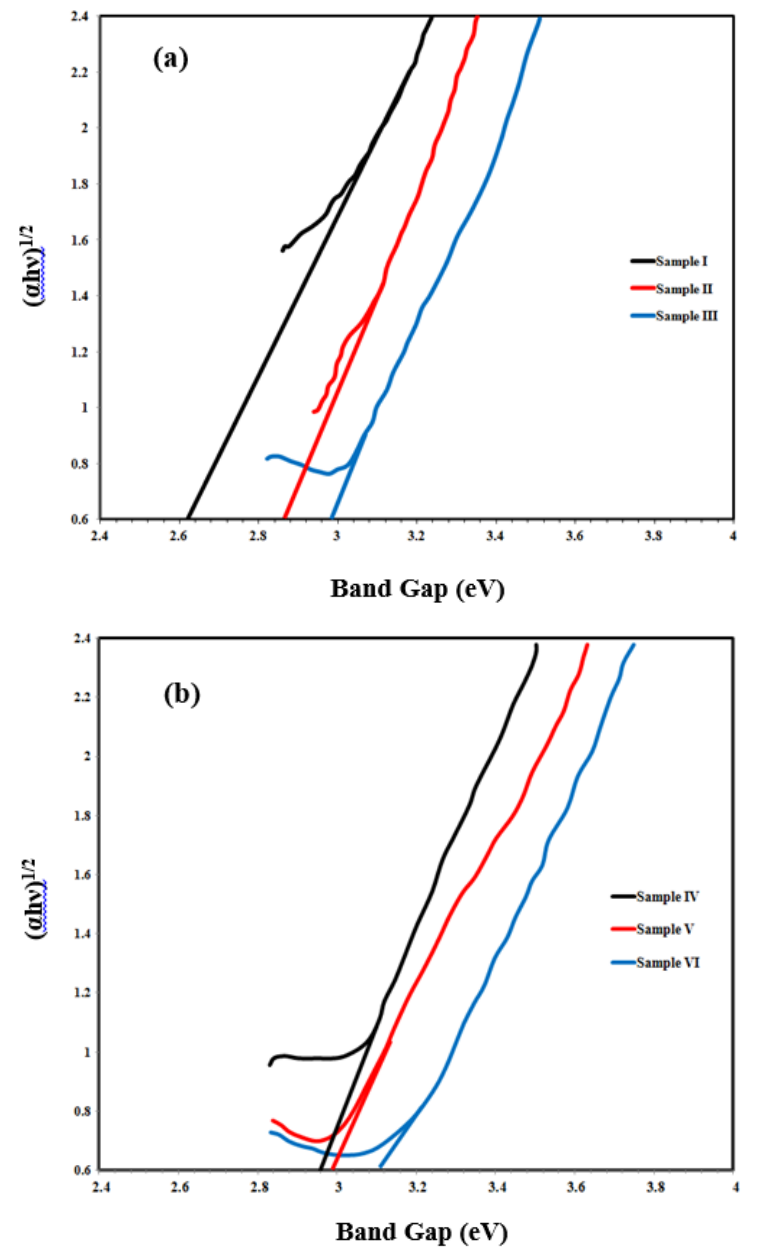

FIG. 3. Optical absorption curve of tungsten oxide films deposited at different oxygen flow rates in (a) argon and (b) helium atmospheres.

the optical band gap of the RF magnetron sputtered $\mathrm{WO}_{3}$ films increases from $2.76 \mathrm{eV}$ to $3.07 \mathrm{eV}$ as the oxygen content increased from $10 \%$ to $40 \%$ in the sputter chamber [13].

Mohamed et al. reported that the band gap of the films increased from $2.90 \mathrm{eV}$ to $3.18 \mathrm{eV}$ with the increase of oxygen partial pressure from $0.20 \mathrm{~Pa}$ to $0.52 \mathrm{~Pa}$ [23]. Figures 3(a) and 3(b) show the result between $(\alpha h \nu)^{1 / 2}$ and $h \nu$ for the samples deposited at different oxygen flow rates in argon and helium atmospheres, respectively. The calculated band gap values are shown in Table II.

\section{Electrochromic properties}

By using CV, the electrochromic property of the $\mathrm{WO}_{3}$ thin film has been examined. A voltage between $-2.0 \mathrm{~V}$ to $+2.0 \mathrm{~V}$ is applied relative to $\mathrm{Ag} / \mathrm{AgCl}$ with a scan rate of $0.02 \mathrm{mV} \mathrm{s}^{-1}$ during CV analysis. Figure $4(\mathrm{a}, \mathrm{b})$ shows the $\mathrm{CV}$ of the $\mathrm{WO}_{3}$ films deposited in argon and helium atmospheres at different oxygen flow rate. It was found that the $\mathrm{WO}_{3}$ films have a tendency to reverse the color. It was observed that the film deposited at lower oxygen flow rate shows a higher current density under the same voltage applied condition. It was also found that with the increase in oxygen flow rate, the current density starts
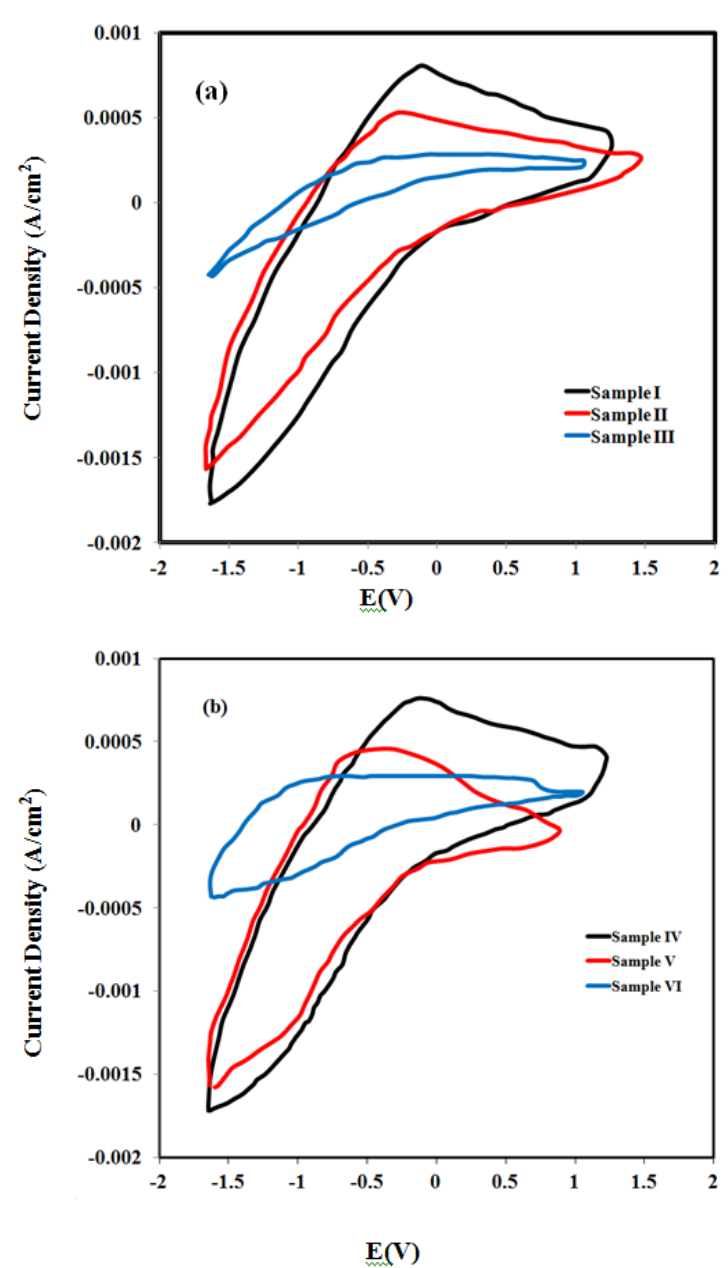

FIG. 4. Cyclic voltammetric curve of tungsten oxide films deposited at different oxygen flow rates in (a) argon and (b) helium atmospheres.

decreasing. The reason for this may be attributed to the decrease in the number of incident sputtering gas ions on the tungsten target with an increase in oxygen flow rate. The decrease in oxygen flow rate increases the deposition rate (evident from Table II), which clearly suggest an increase in the number of argon ions hitting the tungsten target $[24,25]$.

\section{CONCLUSION}

In summary, we have successfully demonstrated the feasibility of depositing $\mathrm{WO}_{3}$ films by radio frequency magnetron sputtering in the presence of two different inert gases (argon and helium) with varying oxygen flow rates by keeping the other sputtering parameters constant. The average crystallite size and thickness of $\mathrm{WO}_{3}$ films increase when samples are deposited in argon atmosphere as compared to helium atmosphere. It was also observed that as the oxygen flow rate increases, the band gap also increases. The film deposited at lower oxygen flow rate shows a higher current density under the same voltage applied condition. The $\mathrm{WO}_{3}$ films are hydrophobic by nature without losing transparency of films, and as the surface roughness increases, the contact angle increases. 


\section{List of Symbols}

$\begin{array}{ll}{ }^{\circ} \mathrm{C} & \text { degree Celsius } \\ \AA & \text { Angstrom } \\ E_{\mathrm{g}} & \text { energy band-gap } \\ \mathrm{eV} & \text { electronvolt } \\ \mathrm{h} & \text { hour } \\ \mathrm{Pa} & \text { pascal } \\ \mathrm{mm} & \text { millimeter } \\ \mathrm{W} & \text { watt } \\ \mathrm{nm} & \text { nanometer } \\ \mathrm{s} & \text { second } \\ t & \text { time } \\ T & \text { transmittance } \\ \lambda & \text { wavelength } \\ \theta & \text { incident angle } \\ h \nu & \text { photons of energy } \\ \text { sccm } & \text { standard cubic centimeters per minute }\end{array}$
Abbreviations

$\begin{array}{ll}\text { CV } & \text { cyclic-voltammetry } \\ \text { RF } & \text { radio frequency } \\ \text { UV-Vis } & \text { ultraviolet visible } \\ \text { XRD } & \text { X-ray diffraction }\end{array}$

\section{ACKNOWLEDGMENTS}

This work has been supported by AICTE grant number 20/AICTE/RIFD/RPS (POLICYIII)24/2012-13 sanctioned under Research Promotion Scheme (RPS). We are thankful to Dr. K. C. Patel, the Head of the Research and Development Centre (KRADLE) affiliated to the Charotar University of Science and Technology (CHARUSAT), Anand, Gujarat, India for granting permission to use various equipment available in their characterization laboratory.
[1] T. Polcar, N. M. G. Parreira, and A. Cavaleiro, Vacuum 81, 1426 (2007)

[2] A. Di Paola, F. Di Quarto, and C. Sensuri, J. Electrochem. Soc. 125, 1344 (1978).

[3] M. Regragui, V. Jousseaume, M. Addou, A. Outzourhit, J. C. Bernede, and B. El Idrissi, Thin Solid Films 397, 238 (2001).

[4] S. Balaji, Y. Djaoued, A. Albert, and R. Bruning, J. Mater. Chem. 21, 3940 (2011).

[5] K. Iwata, P. Fons, S. Niki, A. Yamada, K. Matsubara, K. Nakahara, T. Tanabe, and H. Takasu, J. Cryst. Growth 214-215, 50 (2000).

[6] L. Horng-Hwa, J. Alloys Compd. 465, 429 (2008).

[7] I. Riech, M. Acosta, J. L. Pena, and P. Bartolo-Perez, J. Vac. Sci. Technol. A 28, 329 (2010).

[8] K. Aguir, C. Lemire, and D. B. B. Lollman, Sens. Actuators B 84, 1 (2002).

[9] A. Yamamoto, Y. Abe, M. Kawamura, and K. Sasaki, Vacuum 66, 269 (2002).

[10] G. A. Niklasson, L. Berggren, and A. L. Larsson, Sol. Energy Mater. Sol. Cells 84, 315 (2004).

[11] M. Gillet, C. Lemire, E. Gillet, and K. Aguir, Surf. Sci. 532-535, 519 (2003).

[12] C. Lemire, D. B. B. Lollman, A. Al Mohammad, E. Guillet, and K. Aguir, Sens. Actuators B 84, 43 (2002).

[13] A. K. Chawla, S. Singhal, H. O. Gupta, and R. Chandra, Thin Solid Films 517, 1042 (2008).
[14] B. D. Cullity, Elements of X-ray Diffraction, 2nd Ed. (Addison-Wesley, London, 1978) p. 102.

[15] R. Chandra, A. K. Chawla, and P. Ayyub, J. Nanosci. Nanotechnol. 6, 1119 (2006).

[16] A. Subrahmanyam and A. Karuppasamy, Sol. Energy Mater. Sol. Cells 91, 266 (2007).

[17] A. Rougier, F. Portemer, A. Quédé, and M. El Marssi, Appl. Surf. Sci. 153, 1 (1999).

[18] J. C. Manifacier, J. Gasiot, and J. P. Fillard, J. Phys. E: Sci. Instrum. 9, 1002 (1976).

[19] J. Tauc, in: Amorphous and Liquid Semiconductor, edited by J. Tauc (Plenum Press, New York, 1974) p. 159.

[20] N. A. Hegab, A. E. Bekheet, M. A. Afifi, and A. A. ElShazly, Appl. Phys. A 66, 235 (1998).

[21] N. R. Aghamalyan, I. A. Gambaryan, E. K. Goulanian, R. K. Hovsepyan, R. B. Kostanyan, S. I. Petrosyan, E. S. Vardanyan, and A. F. Zerrouk, Semicond. Sci. Technol. 18, 525 (2003).

[22] H. Irie, Y. Watanabe, and K. Hashimoto, J. Phys. Chem. B 107, 5483 (2003).

[23] S. H. Mohamed, H. A. Mohamed, and H. A. Abd El Ghan, Physica B 406, 831 (2011).

[24] A. Kaushal and D. Kaur, J. Nanopart. Res. 13, 2485 (2011).

[25] C. Chanannawathorn, S. Pudwat, M. Horprathum, P. Eiamchai, P. Limnontakul, C. Salawan, and K. Aiempankit, Procedia Engineering 32, 752 (2012). 